\title{
Mobile acoustic transects miss rare bat species: Implications of survey method and spatio-temporal sampling for monitoring bats
}

\author{
Elizabeth Claire Braun de Torrez ${ }^{\text {Corresp., }}{ }^{1}$, Megan A Wallrichs ${ }^{1}{ }^{\text {, }}$ Holly K Ober ${ }^{1}$ ， Robert A McCleery $^{1}$ \\ ${ }^{1}$ Department of Wildlife Ecology and Conservation, University of Florida, Gainesville, Florida, United States of America \\ Corresponding Author: Elizabeth Claire Braun de Torrez \\ Email address: ecbraun@ufl.edu
}

Due to increasing threats facing bats, long-term monitoring protocols are needed to inform conservation strategies. Effective monitoring should be easily repeatable while capturing spatio-temporal variation. Mobile acoustic driving transect surveys ('mobile transects') have been touted as a robust, cost-effective method to monitor bats; however, it is not clear how well mobile transects represent dynamic bat communities, especially when used as the sole survey approach. To assist biologists who must select a single survey method due to resource limitations, we assessed the effectiveness of three acoustic survey methods at detecting species richness in a vast protected area (Everglades National Park): (1) mobile transects, (2) stationary surveys that were strategically located by sources of open water and (3) stationary surveys that were replicated spatially across the landscape. We found that mobile transects underrepresented bat species richness compared to stationary surveys across all major vegetation communities and in two distinct seasons (dry/cool and wet/warm). Most critically, mobile transects failed to detect three rare bat species, one of which is federally endangered. Spatially replicated stationary surveys did not estimate higher species richness than strategically located stationary surveys, but increased the rate at which species were detected in one vegetation community. The survey strategy that detected maximum species richness and the highest mean nightly species richness with minimal effort was a strategically located stationary detector in each of two major vegetation communities during the wet/warm season. 
2 Mobile acoustic transects miss rare bat species: Implications of survey method and spatio-

3 temporal sampling for monitoring bats

4

5 Elizabeth C. Braun de Torrez ${ }^{1 *}$, Megan A. Wallrichs ${ }^{1}$, Holly K. Ober ${ }^{1}$ and Robert A. McCleery ${ }^{1}$

6

$7 \quad{ }^{1}$ Department of Wildlife Ecology and Conservation, University of Florida, Gainesville, FL,

8 United States of America

9

10 *Corresponding author: Elizabeth C. Braun de Torrez

11 ecbraun@ufl.edu 


\section{Abstract}

13 Due to increasing threats facing bats, long-term monitoring protocols are needed to inform

14 conservation strategies. Effective monitoring should be easily repeatable while capturing spatio-

15 temporal variation. Mobile acoustic driving transect surveys ('mobile transects') have been

16 touted as a robust, cost-effective method to monitor bats; however, it is not clear how well

17 mobile transects represent dynamic bat communities, especially when used as the sole survey

18 approach. To assist biologists who must select a single survey method due to resource limitations,

19 we assessed the effectiveness of three acoustic survey methods at detecting species richness in a

20 vast protected area (Everglades National Park): (1) mobile transects, (2) stationary surveys that

21 were strategically located by sources of open water and (3) stationary surveys that were

22 replicated spatially across the landscape. We found that mobile transects underrepresented bat

23 species richness compared to stationary surveys across all major vegetation communities and in

24 two distinct seasons (dry/cool and wet/warm). Most critically, mobile transects failed to detect

25 three rare bat species, one of which is federally endangered. Spatially replicated stationary

26 surveys did not estimate higher species richness than strategically located stationary surveys, but

27 increased the rate at which species were detected in one vegetation community. The survey

28 strategy that detected maximum species richness and the highest mean nightly species richness

29 with minimal effort was a strategically located stationary detector in each of two major

30 vegetation communities during the wet/warm season.

\section{Introduction}

33 Effective methods to survey wildlife populations are critical to document changes in biodiversity

34 and develop appropriate management actions. These surveys must be easily repeatable over time 
35 while still capturing the inherent variation in a population or community. However, surveys can

36 be logistically complicated and costly, particularly in large or remote areas that are difficult to

37 access (Conn et al. 2016). Bats (Order Chiroptera) are a taxonomic group that are challenging to

38 survey due to their elusive nocturnal behavior, and ability to fly over vast landscapes. Bats

39 provide important pollination, seed dispersal and pest suppression services (Kunz et al. 2011);

40 yet the long-term provisioning of these services is uncertain due to sharp declines of bats

41 worldwide from habitat loss, emerging pathogens and wind energy development (Fisher et al.

42 2012; Hayes 2013; Mickleburgh et al. 2002). Long-term monitoring protocols need to be

43 developed to document bat population trends and inform conservation strategies (O'Shea et al.

$44 \quad 2003)$

45 Techniques to acoustically detect and identify bats have improved over the past several

46 decades (Britzke et al. 2013; Parsons \& Szewczak 2009), allowing documentation of species

47 distributions, habitat preferences, activity patterns, and presence of endangered species (e.g.,

48 (Britzke et al. 2002; Jaberg \& Guisan 2001; Wickramasinghe et al. 2003; Williams et al. 2006).

49 However, it is still not clear how best to use acoustic surveys to monitor bat communities (Hayes

50 et al. 2009). Specifically, we do not know the temporal and spatial sampling effort necessary to

51 represent the heterogeneity in bat activity and species composition across landscapes (Britzke et

52 al. 2013; Loeb et al. 2015). Nightly variation in bat activity can result in misrepresentation of the

53 species assemblage in a site if not sufficiently sampled temporally (Hayes 1997; Law et al. 2015;

54 Milne et al. 2005; Skalak et al. 2012). Similarly, spatial heterogeneity can lead to different

55 estimates of bat activity and species richness, even among acoustic detectors located within the

56 same vegetation stand (Britzke 2003; Duchamp et al. 2006; Fischer et al. 2009; Froidevaux et al.

57 2014). Recommendations for duration and spatial stratification of surveys have varied widely 
58 among studies (Bean \& Rowland 1997; Britzke et al. 2013; Coleman et al. 2014; Froidevaux et

59 al. 2014; Rodhouse et al. 2011; Stahlschmidt \& Brühl 2012).

Two primary acoustic survey methods are frequently recommended for use in bat

61 monitoring protocols: stationary acoustic point surveys (hereafter 'stationary surveys'), and

62 mobile acoustic driving transect surveys (hereafter 'mobile transects') (e.g., North American Bat

63 Monitoring Program (NABat); (Loeb et al. 2015). Stationary surveys and mobile transects each

64 have their respective advantages (Table 1), and are often encouraged to be used together (Loeb et

65 al. 2015). However, there are many cases in which limited funding, equipment and time may

66 require biologists to select only one method. Despite the prevalent use of both stationary surveys

67 and mobile transects, the relative efficacy of each method has rarely been compared for bats (but

68 see Whitby et al. 2014). Mobile transects are considered by some to be a robust and cost-

69 effective method to monitor bat populations (Battersby 2010; Catto et al. 2003; Roche et al.

70 2011; Whitby et al. 2014). Because most bat species fly slower than the recommended speed of a

71 survey vehicle (32 km/h) (Hayward \& Davis 1964; Patterson \& Hardin 1969), each recorded bat

72 pass should represent a unique individual, allowing estimates of relative abundance (Roche et al.

73 2011) that cannot be derived from stationary detectors (Hayes 2000). However, mobile transects

74 may misrepresent patterns of bat community composition if use of roads or roadside habitat

75 differs among species (Anderson 2001; Linton 2009; Roche et al. 2011; Zurcher et al. 2010). Of

76 particular concern is that, globally, many large protected areas are remotely located with limited

77 access to roads (Joppa \& Pfaff 2009), thereby restricting the potential areas in which mobile

78 transects can sample the bat community. Further, mobile transects typically only sample a few

79 hours after sunset each night for a limited number of nights each season (Loeb et al. 2015), and,

80 because the vehicle is moving, sample only briefly at any given location. These sources of 
81 limited temporal and spatial sampling inherent to mobile survey efforts could lead to

82 underestimates of species richness (Skalak et al. 2012), and an inability to detect trends in rare

83 species activity or abundance (Jones et al. 2013).

84 Species richness is widely used as a metric for biodiversity surveys (Purvis \& Hector 2000),

85 monitoring programs (Yoccoz et al. 2001) and prioritizing conservation areas (Howard et al.

86 2000). Identification of the most effective survey methods and sample effort to detect species

87 richness across landscapes is prudent given limited conservation resources. To assist biologists

88 who must select a single survey method, we compared the relative effectiveness of two

89 commonly used, but rarely compared, acoustic survey methods (mobile transect and stationary

90 surveys) at detecting bat species richness in a vast protected area suspected to contain rare and

91 endangered bat species (Everglades National Park [ENP]). We then focused on two types of

92 stationary surveys to assess how spatial replication (surveys at multiple sites) influenced

93 estimates of species richness within two structurally different vegetation communities.

94 Specifically, we compared: "single strategic stationary surveys" - a single detector strategically

95 located near an open water source to maximize bat detections, to "spatially replicated stationary

96 surveys" - multiple detectors distributed across each vegetation community to capture spatial

97 heterogeneity in the bat community. Finally, we estimated the minimum required temporal

98 sampling effort for each method to detect maximum species richness. Seasonal flooding, limited

99 road access and poor knowledge of the bats in ENP make it challenging to design an effective

100 bat monitoring protocol, yet is representative of many remote, conservation areas worldwide.

101

102 Materials and methods 
103 All field methods for this study were approved by the United States Department of the Interior,

104 National Park Service, Everglades National Park (permit number: EVER-2015-SCI-0009).

106 Study Area

107 This study was conducted in ENP, situated at the southern end of the vast freshwater

108 wetland of the Greater Everglades Ecosystem in South Florida, U.S.A. ENP encompasses

109610,484 ha of federally protected lands and is designated an International Biosphere Reserve, a

110 World Heritage Site and a Wetland of International Importance in the Ramsar Convention

111 (Maltby \& Dugan 1994). ENP is characterized by two distinct seasons: dry/cool (December to

112 April) when average monthly precipitation $(42-47 \mathrm{~mm})$ and average temperatures $\left(12-25^{\circ} \mathrm{C}\right)$

113 are relatively low, and wet/warm (May to November) when the majority of the annual

114 precipitation falls $\left(62-200 \mathrm{~mm}\right.$ per month) and average temperatures are high $\left(18-32^{\circ} \mathrm{C}\right)$

115 (Duever et al. 1994; Lodge 2010). The three dominant vegetation communities in ENP include

116 pine rocklands (hereafter 'pinelands'), freshwater sawgrass marshes and wet prairies (hereafter

117 'prairies'), and mangrove swamps (hereafter 'mangroves') (Florida Natural Areas Inventory ;

118 Lodge 2010). Access is greatly limited by the restriction of terrestrial motor vehicle access in the

119 park to one paved road, and also the seasonal flooding that extends across much of the park.

120 Very little is known about bat community composition in ENP (Lodge 2010). Based on

121 range maps (Florida Fish and Wildlife Conservation Commission 2016; IUCN 2015), at least

122 seven species of bats likely occur in ENP: big brown bats (Eptesicus fuscus), Florida bonneted

123 bats (Eumops floridanus), Seminole bats (Lasiurus seminolus), northern yellow bats ( $L$.

124 intermedius), evening bats (Nycticeius humeralis), tri-colored bats (Perimyotis subflavus), and

125 Brazilian free-tailed bats (Tadarida brasiliensis). Four of these species (tricolored bats, Florida 
126 bonneted bats, Seminole bats, and big brown bats) are considered to be uncommon or rare in

127 ENP (Florida Fish and Wildlife Conservation Commission 2016), and one is of particular

128 concern (Florida bonneted bat), due to its status as endemic to South Florida and Federally

129 Endangered (United States Fish and Wildlife Service 2013). Four additional species have

130 geographic ranges within south Florida that could possibly extend into the park: velvety free-

131 tailed bats (Molossus molossus), southeastern myotis (Myotis austroriparius), eastern red bats ( $L$.

132 borealis) and Rafinesque's big-eared bats (Corynorhinus rafinesquii).

134 Acoustic Surveys

135 We implemented three types of acoustic survey methods (one mobile and two stationary)

136 that took into account the major vegetation communities and accessibility to survey locations: (1)

137 mobile transects, (2) single strategic stationary surveys, and (3) spatially replicated stationary

138 surveys (Fig. 1A). We selected ultrasonic recording equipment designed and recommended for

139 use in stationary and mobile acoustic monitoring studies (Loeb et al. 2015). Stationary surveys

140 were conducted with full spectrum Song Meter SM3BAT detectors and external ultrasonic

141 microphones (SM3-U1; Wildlife Acoustics, Inc.) extended to $3 \mathrm{~m}$ above ground level. We

142 conducted mobile transects using a full spectrum Echo Meter EM3+ detector and external

143 ultrasonic microphone (SMX-UT; Wildlife Acoustics, Inc.) mounted on the top of our vehicle,

144 and connected a Global Positioning Satellite (GPS) unit to the detector to record GPS

145 coordinates for each acoustic file. Prior to deployment of all equipment, we used an Ultrasonic

146 Calibrator (Wildlife Acoustics, Inc), designed to verify the sensitivity of the microphones and

147 overall system performance. We collected data with the three methods within a 40-night 
148 sampling period (details below) in each of two distinct seasons during 2015: dry/cool (February

$149-$ March) and wet/warm (June - July).

150 Method 1: Mobile Transect Surveys. We used the only existing paved park road from the

151 main ENP entrance gate to Flamingo $(64 \mathrm{~km})$, which traverses the three vegetation communities:

152 pinelands, prairies and mangroves (Fig. 1A). Transects were driven at a constant $32 \mathrm{~km} / \mathrm{h}$,

153 beginning 30 minutes after sunset (Loeb et al. 2015; United States Fish and Wildlife Service

154 2012), for a survey duration of two hours. We surveyed the transect nine times in the dry season

155 and ten times in the wet season, each within a 40-night sampling period (ca. once every five

156 nights), alternating the start location between each end of the transect road for each survey. We

157 selected a sample effort much greater than the two survey nights per maternity season

158 recommended by the widely-implemented NABat protocol (Loeb et al. 2015), to estimate the

159 number of survey nights necessary to detect maximum species richness in the study area. We did

160 not survey on nights when average wind speeds exceeded $24 \mathrm{~km} / \mathrm{h}$ (United States Fish and

161 Wildlife Service 2012), but allowed for wind gusts up to $30 \mathrm{~km} / \mathrm{h}$ due to consistently high coastal

162 wind conditions. Due to frequent but often short-duration rain events in south Florida, we paused

163 each survey when precipitation began and waited for it to pass. If the survey was paused for

164 more than 15 mins cumulatively, we ended the survey and repeated it the following night. We

165 assigned each bat detected during a mobile transect to the vegetation community in which it was

166 recorded, using that file's associated GPS coordinates (ArcMap v10.2.2; Florida Cooperative

167 Land Cover Map v3.1).

168 Method 2: Single Strategic Stationary Surveys. We established one easily accessible,

169 strategically-located stationary monitoring station designed to remain permanently in each of the

170 three vegetation communities: pinelands, prairies, and mangroves (Fig. 1A). To maximize bat 
171 detections and the quality of recordings, we located each detector within $10 \mathrm{~m}$ of a water source,

172 but away from vegetative clutter and flat surfaces prone to acoustic echoes (Britzke et al. 2013;

173 Loeb et al. 2015). Detectors were powered by solar panels, mounted with custom made

174 structures constructed from PVC pipes and angle iron, and programmed to record from 30 mins

175 before sunset to 30 mins after sunrise (12-hr mean survey duration/night over the study). We set

176 the detectors to record for 40 nights in each season.

177 Method 3: Spatially Replicated Stationary Surveys. To assess how increasing sample

178 effort spatially would affect estimated bat species richness and how that may differ between

179 structurally distinct vegetation communities, we focused on pinelands (small, dry, closed canopy

180 system) and prairies (vast, wet, open canopy system), two relatively easy to access vegetation

181 communities. We did not sample in mangroves due to high water levels year round that would

182 require additional equipment (e.g., airboats) for these surveys to be conducted. We sampled a

183 total of six locations in pinelands (2 - $12 \mathrm{~km}$ apart) and six locations in prairies ( $8-45 \mathrm{~km}$ apart),

184 distributing sample locations as evenly as possible throughout each vegetation community $(\geq 300$

$185 \mathrm{~m}$ from the habitat edge), while ensuring that each location was accessible by foot year round (10

$186-300 \mathrm{~m}$ from a secondary road or path, $100-3,500 \mathrm{~m}$ from a primary road) (Fig. 1A). We

187 mounted detectors and microphones on painter's poles (3 $\mathrm{m}$ above ground) and selected sites

188 where the recording space above microphones was unobstructed by vegetative clutter. We

189 programmed detectors to record from 30 mins before sunset to 30 mins after sunrise (12-hr mean

190 survey duration/night over the study). In each season, we conducted two 20-night sampling

191 sessions. During each 20-night sampling session we placed three detectors in pinelands and three

192 detectors in prairies and then moved these detectors to six new locations for the second 20 night

193 sampling session. The same 12 locations were surveyed during both the wet and dry seasons. 
195 Acoustic Analysis and Species Identification

196 We used Kaleidoscope Pro 3.14B (Wildlife Acoustics, Inc.) for automated noise (non-bat

197 ultrasound) filtering, species classifications and to manually review the spectrograms of acoustic

198 files. We used the 'Bats of Florida Classifier' (beta v.3.1.0) and 'Bats of the Neotropics' (v.3.1.3)

199 in Kaleidoscope Pro to identify calls from all possible species in the region. Species with

200 indistinguishable calls (eastern red bats and Seminole bats) were considered as one species group.

201 Current classifiers in Kaleidoscope Pro can not identify Rafinesque's big-eared bats; hence, we

202 used Townsend's big-eared bats (Corynorhinus townsendii) as a proxy, given the similarity in

203 call structure between the two species (Szewczak 2011). To minimize species identification error

204 and false positives (Lemen et al. 2015), we developed a conservative protocol to positively

205 identify species with infrequent detections and to filter out ambiguous and/or low quality bat

206 calls. We required that all files that were given an ultimate species classification had $\geq 5$ total

207 calls and that $\geq 75 \%$ of the calls in each of these files matched the ID assigned by Kaleidoscope

208 Pro. To confirm species identifications of files that met our criteria, we manually reviewed: 1)

209 any unexpected species classifications based on species range maps, 2) any species with $<10$

210 files at a given detector location and 3) all files identified as southeastern myotis, velvety free-

211 tailed bats or Rafinesque's big-eared bats due to distribution uncertainty for these species.

212 Finally, due to the status of Florida bonneted bats as an endangered species and their easily

213 identifiable echolocation calls, we manually reviewed $100 \%$ of the files classified by

214 Kaleidoscope Pro as Florida bonneted bats, NoID, or Noise. We also reviewed all ambiguous

215 files for which the software provided multiple species identifications including Florida bonneted

216 bats (i.e., Florida bonneted bat was listed as an 'Alternate' species). We only included files that 
217 we unambiguously identified as Florida bonneted bat calls and did not overlap with Brazilian

218 free-tailed bats' frequency range $(<18 \mathrm{khz})$. To aid in manual validation, we compiled a

219 reference library of echolocation calls from hand-released bats captured in mist nets in south

220 Florida and other areas in the southeastern U.S., as well as from publicly available databases and

221 journal articles (e.g., (Jung et al. 2014; Marks \& Marks 2006; Szewczak 2011). To reduce

222 subjectivity, two researchers experienced in identification of bat calls independently confirmed

223 all manually validated calls. Our automated and manual validation protocols were used

224 consistently across detectors; thus, despite some expected identification error, we were able to

225 compare the relative ability of each survey method to detect species richness.

227 Statistical Analysis

228 All graphical and statistical analyses were conducted in the statistical software R (v.

229 3.1.2) with R studio (v. 0.98.1102). All reported errors are standard error of the mean $( \pm \mathrm{SE})$

230 unless otherwise noted. To evaluate the effectiveness of the three survey methods at representing

231 bat community composition, at each detector we quantified: 1) total species richness (number of

232 species) detected over the entire study, and 2) nightly species richness (number of species

233 standardized by survey night to account for uneven temporal sampling among survey methods).

$234 \quad$ Survey method. First, we did a simple comparison of the species (and total species

235 richness) detected by all three methods in each survey location in each season. To account for the

236 limited temporal sampling by mobile transects relative to stationary surveys, and to identify

237 potential reasons for differences in species detections, we subsequently restricted this

238 comparison to: a) the nights, b) the nights and times when mobile transects were conducted. 
Next, we compared nightly species richness between mobile transects and single strategic

240 stationary surveys only, to test the effectiveness of these two methods across the three primary

241 vegetation communities. To account for the greater number of nights sampled by the stationary

242 surveys, we limited our comparison to only the nights when mobile transect surveys were

243 conducted. Although the number of recording hours per night was less for mobile transects than

244 stationary surveys, we used 'survey night' as our sample unit based on existing survey protocols

245 and what is typically used in the field (Loeb et al. 2015; United States Fish and Wildlife Service

246 2012). In the practical application of these survey methods, mobile transects are never conducted

247 all night, and stationary surveys are generally always conducted for the full night. We

248 constructed generalized linear mixed-effects models (GLMMs), with vegetation community and

249 season as random effects (function glmer, R package lme4 (Bates et al. 2012)). We modeled all

250 GLMMs with a Poisson distribution for count data, after assessing model fit using standard

251 graphical diagnostics of residuals (Zuur et al. 2009) and testing for over-dispersion (function

252 dispersion_glmer, R package blmeco (Korner-Nievergelt et al. 2015)). To test for the effect of

253 survey method, we compared two nested models (one with survey method included and one

254 without) using a likelihood ratio test (function anova, R Stats package).

255 Sample effort. To evaluate how spatially increasing sample effort within vegetation

256 communities affected the estimated species richness, we compared the two stationary survey

257 methods in pinelands and prairies and used the entire sampling period (40 nights in each season).

258 We compared the nightly species richness that was detected by single strategic and spatially

259 replicated stationary surveys. We constructed GLMMs (Poisson distribution), with survey

260 method and vegetation community as fixed effects and season and individual detector as random

261 effects (categorical variables), and used likelihood ratio tests to evaluate the effect of survey 
262 method. We then used the same approach to test for differences between survey methods within

263 pinelands and prairies to determine if there was a difference in the effectiveness of spatial

264 replication in two structurally distinct vegetation communities.

265 Species accumulation curves. To further compare survey methods and to estimate the

266 minimum temporal and spatial sampling effort necessary to detect maximum expected species

267 richness, we generated sample-based rarefaction species accumulation curves (SAC) (Gotelli \&

268 Colwell 2001), using the function 'specaccum' in the R package Vegan. We used the default

269 'exact' method, which estimates the expected species richness using a sample-based rarefaction

270 method (Chiarucci et al. 2008; Kindt et al. 2006) and is often known as the Mao Tau estimate

271 (Colwell et al. 2012). Maximum expected species richness is estimated at the point that SACs

272 reach an asymptote, or the probability of detecting new species approaches zero. Rarefaction

273 curves can be used to compare the efficacy of different sampling methods within an area (Ellison

274 et al. 2007; Longino 2002). We used a simple, but approximate, method to compare SACs

275 among survey methods by looking at the degree of overlap in confidence intervals $(\mathrm{CI})($ Gotelli \&

276 Colwell 2011). To do this, we calculated unconditional standard deviations (Colwell et al. 2004;

277 Colwell et al. 2012), which are not conditioned on the empirical data set but are instead based on

278 an estimation of the extrapolated number of species in the regional species pool (i.e., assumes the

279 sample is randomly drawn from a larger, unknown, species assemblage [gamma diversity];

280 function specpool). We then plotted $84 \%$ confidence intervals ( $c i=1$ in function specaccum) for

281 each SAC, which are more appropriate for tests of overlap than traditional 95\% CI, assuming

282 approximately equal CIs (Gotelli \& Colwell 2011; Payton et al. 2003). To compare SAC overlap

283 between single strategic stationary surveys and mobile transects, we limited the sample effort to

284 the same number of nights for each method by generating a random subsample, without 
285 replacement, of single strategic stationary survey nights ( 9 in the dry season and 10 in the wet

286 season). To determine the temporal sample effort required to detect all bat species using each

287 survey method in each of the two seasons, we used the full sample period and plotted SACs with

288 number of survey nights as the sample unit. Multiple detectors within each survey method

289 ( ingle strategic $=3$; spatially replicated $=12$ ) were pooled for these analyses. To assess how

290 required temporal sample effort varied by vegetation community, we plotted SACs within

291 pinelands and prairies for the two stationary survey methods. Finally, to determine the minimum

292 spatial sample effort required to detect all bat species using the spatially replicated stationary

293 surveys in each season, we plotted SACs in pinelands and prairies with number of detector sites

294 as the sample unit.

295

296 Estimated survey effort and costs.

297 To provide biologists with a relative comparison of the labor and expenses associated

298 with each survey method in our study, we estimated the total Effort (person-hours to the nearest

299 hour) and Cost (to the nearest \$10) required for data collection and analysis for one season (40-

300 night sampling period). We estimated Effort required for fieldwork (driving, deploying/removing

301 equipment, changing batteries/data cards), and analysis (automated species ID and manual

302 validation, but not statistical analyses). We estimated Cost required for equipment (detectors,

303 microphones, batteries, data cards, acoustic analysis software), vehicle (current State of Florida

304 vehicle reimbursement rate of $\$ 0.45 / \mathrm{mile}$ ), and personnel (technician pay rate of $\$ 12.00 / \mathrm{hr}$ ). To

305 account for uneven temporal sample effort among survey methods, we then standardized the

306 estimated costs by the number of survey nights.

307 


\section{Results}

309 During one dry/cool and one wet/warm season, we recorded acoustic data from 720

310 detector nights (40 nights * 3 single strategic detector sites * 2 seasons; 20 nights * 12 spatially

311 replicated detector sites * 2 seasons) with stationary surveys and 19 detector nights (19 nights * 1

312 detector) with mobile transect surveys. Due to equipment malfunction, data were not useable

313 from one night of mobile transect data in the dry season and ten nights of data in both seasons for

314 the single stationary detector in the prairie. We recorded 193,252 total acoustic files. After

315 removing files determined to be non-bat ultrasonic or acoustic noise (e.g., wind, insects, birds),

316151,259 files containing bat sequences remained for analyses (single strategic $=76,521$; spatially

317 replicated $=73,461$; mobile transect $=1,277$ ). Using our conservative protocol and manual

318 validation, we identified 42,669 files (28.2\% of total bat files) to the level of species or species

319 group $($ single strategic $=16,384$; spatially replicated $=26,054$; mobile transects $=231)$. In total,

320 we detected nine bat species (eight species and one species group): Rafinesque's big-eared bats,

321 big brown bats, Florida bonneted bats, eastern red bats and/or Seminole bats, northern yellow

322 bats, velvety free-tailed bats, evening bats, tri-colored bats, and Brazilian free-tailed bats. The

323 species richness detected varied by survey method, vegetation community and season (Table 2).

$325 \quad$ Survey method

326 Both single strategic and spatially replicated stationary surveys detected all nine bat

327 species, whereas mobile transect surveys did not detect three of these species at any point during

328 the study: Rafinesque's big-eared bats, Florida bonneted bats, and velvety free-tailed bats (Table

329 2). This finding was consistent even when we limited our comparison of survey methods to only

330 the nights and the specific time window during which transects were conducted (Fig. 1B-D). 
331 Further, mobile transects did not detect tri-colored bats or northern yellow bats in prairies, or big

332 brown bats in pinelands, whereas these species were detected across all vegetation communities

333 by stationary surveys (Table 2). Significantly higher mean nightly bat species richness (number

334 of species present per survey night) was detected by single strategic stationary surveys $(3.59 \pm$

$3350.23)$ than with mobile transect surveys overall $\left(2.02 \pm 0.12 ; \chi^{2}(1)=19.46, p<0.001\right)$,

336 regardless of vegetation community or season. Further, in both dry and wet seasons, the

337 asymptotes and CIs of our species accumulation curves (SACs) indicated that single strategic

338 stationary surveys detected higher expected species richness and accumulated species faster than

339 did mobile transects, even when restricted to the same number of survey nights as mobile

340 transects (Fig. 2); however, we note that the CIs for each SAC differed, which violates one

341 assumption in the use of overlapping CIs to determine inequality between the two methods

342 (Payton et al. 2003).

344 Sample effort for stationary surveys

345 Spatial-survey locations. The same total bat species richness $(\mathrm{N}=9)$ was detected with both

346 stationary survey methods (Table 2). Spatially replicated stationary surveys detected

347 significantly lower mean nightly bat species richness $(2.74 \pm 0.06)$ than did single strategic

348 stationary surveys overall $\left(3.60 \pm 0.10 ; \chi^{2}(1)=8.16, p=0.004\right)$. This result was also found

349 within pinelands $\left(3.23 \pm 0.09\right.$ vs. $\left.4.71 \pm 0.15 ; \chi^{2}(1)=12.18, p<0.001\right)$, but not within prairies

$350\left(2.24 \pm 0.06\right.$ vs. $\left.2.60 \pm 0.09 ; \chi^{2}(1)=0.94, p=0.33\right)$. In both seasons, the overlapping CIs of the

351 SACs indicated that there was no significant difference in expected species richness or rate of

352 species accumulation between single strategic stationary surveys and spatially replicated

353 stationary surveys overall (Fig. 3A-B) and within pinelands (Fig. 3C-D). In contrast, within 
354 prairies in the dry season, the SACs of spatially replicated stationary surveys had higher

355 expected species richness and steeper curves than the SACs from the single strategic stationary

356 surveys (Fig. 3E-F). In the wet season, overlapping CIs indicated no difference in expected

357 species richness between single strategic stationary surveys and spatially replicated stationary

358 surveys, but spatially replicated stationary surveys did not reach an asymptote within the 40-day

359 sampling period indicating insufficient temporal sample effort to detect all species. When

360 evaluating the optimal number of detector sites in spatially replicated stationary surveys,

361 asymptotes were reached on the SACs with only four detector sites in pinelands during both the

362 dry and wet season (Fig. 4). In contrast, spatially replicated stationary surveys in prairies did not

363 reach asymptotes with the six detector sites in either season, indicating that spatial sampling

364 effort was not sufficient.

365

366 Temporal-survey nights. The minimum number of sample nights required to detect expected

367 species richness varied among survey methods, seasons and vegetation communities (Fig. 3).

368 Maximum expected species richness ( $\mathrm{N}=9$ species) was reached only during the wet season

369 with stationary surveys in both pinelands and prairies combined (Fig. 3B). The minimum sample

370 effort required to achieve this was 38 nights for both single strategic stationary surveys and for

371 spatially replicated stationary surveys. Although SAC asymptotes were also reached within the

372 dry season and within each vegetation community, fewer than nine species were detected in each

373 of these categories alone. An asymptote was not reached in prairies for spatially replicated

374 stationary surveys in the wet season after 40 nights of sample effort (Fig. 3F).

375

376 Estimated survey effort and costs 
377 Based on our estimates of total effort and costs associated with the three survey methods,

378 spatially replicated surveys required the most time and cost for collection and analysis of data,

379 costing just over 1.5 times that of single strategic surveys and nearly four times that of mobile

380 transects (Table 3). When standardized by the number of survey nights used in each method, the

381 cost of mobile transects was the greatest per survey night and single strategic surveys the least.

382

383 Discussion

384 We showed that mobile transect surveys underrepresented bat species richness in ENP

385 when compared to species richness detected with stationary surveys conducted on the same

386 nights and during the same time of night. Most critically, mobile transects failed to detect three

387 rare species over the course of the study: Florida bonneted bats (a federally endangered species),

388 Rafinesque's big-eared bats (a species of greatest conservation need at the state level) and

389 velvety free-tailed bats (a species not previously detected in the U.S. outside of the Florida Keys).

390 We also showed that increasing sample effort spatially across the landscape did not result in

391 higher estimates of bat species richness overall, but did increase the rate at which new species

392 were detected in one of two vegetation communities (prairies but not pinelands). Finally, our

393 results indicate that the temporal duration of stationary surveys needs to be long ( $>38$ nights) to

394 detect all bat species in the park, using our conservative identification protocol; thus, it may be

395 more important to maximize temporal sample effort in a few locations rather than increase

396 sample locations spatially.

397

398

Survey method 
400 survey method, particularly in regions with uncommon species and/or in large areas with limited

401 road infrastructure. Given that protected areas worldwide tend to be in isolated locations, far

402 from roads and with limited accessibility (Joppa \& Pfaff 2009), our findings raise concerns that

403 mobile transects may not adequately represent bat communities in these areas. The failure of

404 mobile transects in our study to detect the endangered Florida bonneted bat and two bat species

405 previously undetected in ENP represents a particularly critical weakness of this method (Arroyo-

406 Cabrales \& Álvarez-Castañeda 2008; Florida Fish and Wildlife Conservation Commission 2016;

407 Marks \& Marks 2006; United States Fish and Wildlife Service 2013). Furthermore, our finding

408 that three other bat species (tri-colored, northern yellow and big brown bats) were not detected

409 by mobile transect surveys within all three vegetation communities, as they were by stationary

410 detectors, could result in erroneous conclusions regarding any changes in habitat use by these

411 species.

412 Our results contradict Whitby et al. (2014), who found that mobile transects detected the

413 same species richness as stationary surveys and suggested that mobile transects may account for

414 landscape scale variation across vegetation communities. Our conclusions may differ from

415 Whitby et al. (2014) due to different activity patterns, habitat associations or species-specific

416 abundances of the local bat assemblage sampled in each of our respective study regions. For

417 example, abundant species, uniformly distributed across the landscape, would likely be detected

418 by both survey methods, while rare or patchily distributed species may not. Similar to our study,

419 Whitby et al. (2014) found that stationary surveys had steeper SACs than mobile transects, and

420 thus required fewer survey nights to reach expected species richness. The need for greater 
421 temporal sample effort (survey nights or hours) to reach expected species richness represents an

422 additional cost of mobile transects.

423 The inability of mobile transects to detect rarer bat species in our study may have been

424 due to limited temporal sampling (Skalak et al. 2012), location of roads, possible avoidance of

425 roads by bats (e.g., Roche et al. 2011; Zurcher et al. 2010) or a combination of these factors.

426 Several stationary detectors only detected rare species on nights and at times (i.e., earlier or later

427 in the night) when mobile transects were not being conducted, suggesting that mobile transects

428 missed some rare bat detections due to their limited temporal sampling (see Fig. 1B-D). However,

429 these three species were also detected with several other stationary detectors on the same nights

430 and during the same times when transect surveys were being conducted, indicating that these

431 bats were present on the landscape while the survey vehicle drove the transect route, yet were

432 still missed. Thus, the limited number of survey nights and hours was not the only reason these

433 species were not detected during mobile transects. Rafinesque's big-eared bats were likely

434 missed due to the location of the road on which the transect surveys were conducted; this species

435 was only detected in the northern part of the park, $30 \mathrm{~km}$ from the transect road. In contrast,

436 Florida bonneted bats and velvety free-tailed bats were detected by stationary surveys located

437 near the mobile transect route $(100-200 \mathrm{~m}$ of the road), yet never by mobile transect surveys. It

438 is possible that these two species avoided the road on which we conducted the mobile transect;

439 however, the road had very little traffic $(<10$ vehicles per survey) and no street lights, two

440 features that have been found to negatively affect bat activity (Stone et al. 2009; Zurcher et al.

441 2010). We suggest that there was a spatio-temporal mismatch, in which species that are rare were

442 missed due to the mobile detector only briefly recording in each given location. Similarly,

443 Stahlschmidt and Brühl (2012) found that stationary detectors, when compared to walking 
444 transects, minimized the error associated with spatio-temporal variation in bat activity.

445 Regardless of the reason, completely missing species with mobile transects is concerning given

446 that a primary objective of acoustic surveys is to monitor trends in species and communities, and

447 to inform conservation decisions. Within a park the size of ENP (ca. 600,000 ha.), it is

448 recommended that mobile transects be conducted in multiple locations (e.g., NABat suggests one

449 for every $10 \times 10 \mathrm{~km}$ grid cell); however, this would not be possible in our study area or much of

450 the greater Everglades ecosystem due to limited roads and accessibility. We conducted mobile

451 transect surveys on 19 nights, which, despite being a much greater sample effort than the two

452 survey nights recommended by NABat (Loeb et al. 2015), was not sufficient to detect all nine

453 species detected with stationary surveys. We discourage the use of mobile transects as the

454 primary method for long-term monitoring or assessing community composition of bats in large

455 areas with minimal road access like we find in Everglades National Park. In the case of our study

456 area, mobile transects did not provide any additional benefits to the data obtained from stationary

457 surveys, thus did not warrant the additional cost and effort to conduct them (see Table 3). To

458 circumvent some of the challenges associated with wildlife monitoring in large inaccessible

459 conservation areas, use of alternative non-road based mobile surveys, such as Unmanned Aerial

460 Vehicles (Gonzalez et al. 2016; Linchant et al. 2015) or balloons (McCracken et al. 2008), could

461 be explored for bats. In marine systems, for example, new research suggests that autonomous

462 underwater vehicles coupled with acoustic equipment may provide good coverage both spatially

463 and temporally at a reduced cost compared to that of traditional survey techniques (Klinck et al.

464 2016). However, much more research would first be needed to determine how such methods

465 might alter flight behavior of bats and subsequent interpretation of survey results. 
468 Spatial - survey locations. Contrary to what we expected, spatially replicated stationary

469 surveys detected the same total species richness but lower mean species richness per night than

470 single strategic stationary surveys, with no difference in the rate of species accumulation or

471 estimated species richness overall. Various studies have shown that multiple detectors are

472 necessary to adequately represent the diversity of bats across and within vegetation communities

473 (Ciechanowski et al. 2007; Duchamp et al. 2006; Froidevaux et al. 2014; Jung et al. 2012; Skalak

474 et al. 2012). Our findings suggest that the more labor-intensive survey method of sampling

475 spatially within vegetation communities was not necessary, and that a single detector,

476 strategically located in pinelands and prairies to maximize bat detections, was sufficient. Skalak

477 et al. (2012) suggested that detecting all bat species using a single detector was possible, but

478 improbable in their study area (Mojave Desert, Nevada). Our placement of the single strategic

479 detectors adjacent to bodies of water was likely responsible for the effective sampling of bat

480 species richness. Although water is abundant in ENP, much of it is brackish and/or may be

481 inaccessible to bats for drinking due to dense vegetation impeding flight paths. Because most

482 bats require open sources of fresh water in order to swoop down to drink (Kunz 1982; Taylor \&

483 Tuttle 2007), bats in ENP may congregate around the limited open bodies of fresh water. Our

484 findings support existing recommendations to select stationary survey sites that maximize

485 potential bat activity, which are often near water (Loeb et al. 2015). Many ecosystems worldwide

486 are either truly water limited for bats (e.g., xeric habitats, (Korine et al. 2016) or may appear

487 water rich yet be limited in sources of water that are accessible to bats (e.g, due to dense

488 vegetative clutter, (Ciechanowski et al. 2007; Jackrel \& Matlack 2010). In cases where there are

489 no water bodies available for detector placement or there is limited knowledge of where bats are 
490 most active, spatial replication may be able to substitute for strategic placement of detectors.

491 Increased spatial sampling provided no additional benefits to estimates of species richness

492 in pinelands but it increased the rate at which new species were detected and the maximum

493 estimated species richness detected in prairies. Because prairies are open and wet (Lodge 2010),

494 a given open water source in prairies may be relatively less attractive to bats than an open water

495 source in the drier, structurally complex pinelands. Thus, sampling near water in only one

496 location in the prairies may not be sufficient to fully capture species richness in this community.

497 Similarly, when evaluating the optimal number of detector locations and distribution needed to

498 spatially represent bat communities in ENP, we again observed differences between the two

499 vegetation communities sampled. Our finding that maximum species richness was reached (SAC

500 asymptote) in pinelands with four sites (for 20 nights each) indicates that we adequately sampled

501 spatial heterogeneity in this vegetation community in both dry and wet seasons. Although we

502 found that the single strategic detector was sufficient to detect maximum species richness in

503 pinelands, our estimates of minimum spatial sample effort for pinelands are applicable to

504 monitoring schemes in other similar woodland communities that may not contain (or have access

505 to) sources of water at which to locate detectors. In contrast, spatially replicated stationary

506 surveys in prairies did not ever reach an asymptote in either season, indicating that more than six

507 detectors (for 20 nights each) would be needed to fully represent the bat species richness in this

508 vegetation community. Skalak et al. (2012) similarly found that at least six detector locations

509 were necessary (for ca. 30 nights each) to detect $90 \%$ of bat species in a wetland system. We

510 suggest that prairies in ENP required a greater sample effort than pinelands due to their much

511 larger area and consequently higher heterogeneity in microhabitat and patterns of bat activity and 
512 species distributions, similar to findings by Moreno and Halffter (2000) of a greater sample

513 effort required for bats in a large heterogeneous landscape than in small homogeneous habitats.

514

515 Temporal - survey nights. We found that all nine bat species could be detected with two strategic

516 stationary detectors (one in each of two vegetation communities) after 38 nights of sampling in

517 the wet season when species richness was highest. In contrast, Whitby et al. (2014) detected all

51812 bat species in their study area in Illinois after only 12 nights of sampling (three sample events

519 of four nights each) with stationary detectors. A complete inventory of bat species can require a

520 substantial sample effort (Moreno \& Halffter 2000). Skalak et al. (2012) recommended 20-30

521 sampling nights to detect $80-90 \%$ of the estimated bat species richness (12 species) in Nevada.

522 Froidevaux et al. (2014) recommended a range of 12 to 33 nights for $90 \%$ of estimated species

523 richness (16 species) in Switzerland. In our study, we detected $90 \%$ of the estimated species

524 richness (eight species), after only seven nights of sampling with two strategically placed

525 detectors in the wet season. The relatively low sample effort required to detect $90 \%$ of species in

526 ENP, yet high sample effort required to detect all species is likely due to the presence of rare bat

527 species, which have lower detection probabilities and higher variation in activity levels (Skalak

528 et al. 2012). The variation in optimal survey duration by these studies illustrates that blanket

529 recommendations for monitoring protocols may not be appropriate for all regions, and may need

530 to be fine-tuned based on site-specific factors and project objectives.

\section{Conclusions}

533 Our study highlights concerns with the use of mobile driving transect surveys as a short-

534 term bat survey technique and long-term monitoring protocol. Rare species may not ever be 
535 detected with mobile transects or be detected too infrequently to provide meaningful data on

536 population trends. Similarly, areas with limited roads - such as many national parks, wilderness

537 areas, wildlife refuges, preserves and other vast conservation areas worldwide - may be

538 particularly prone to road biases. Therefore, mobile transects may not accurately capture changes

539 in bat populations/communities over time in these areas, which is the desired outcome of long-

540 term monitoring. In contrast, stationary detectors at strategically selected locations may

541 maximize bat detections and more accurately represent bat community composition and long-

542 term patterns. This method is easily repeatable and requires a lower monetary investment per

543 survey night than mobile transects. However, when conducting stationary surveys in areas

544 containing rare species, such as in our study area, it is important to maximize temporal effort.

545 We suggest that increasing the survey duration in a few strategic locations is a more time and

546 cost-effective approach than increasing the number of survey locations, particularly in areas with

547 accessibility limitations. Finally, our results demonstrate that the efficacy of survey methods can

548 differ depending on the season and vegetation community. We emphasize the importance of field

549 tests to optimize survey method, deployment duration/timing and spatial arrangement of

550 detectors. By weighing survey project goals, resource availability and accessibility to sites,

551 studies like ours will allow managers and researchers to make informed decisions before

552 establishing long-term acoustic monitoring protocols for bats.

553

\section{Acknowledgements}

555 We thank Tylan Dean and Skip Snow from Everglades National Park for coordinating on project

556 design, development and logistics, and for providing valuable input throughout the project. We

557 also thank Kirk Silas for assistance in the field and for valuable discussions about the manuscript. 


\section{Tables and Figures}

559 Table 1. Comparison of the potential advantages and disadvantages associated with two primary

560 acoustic survey methods, mobile driving transect surveys and stationary point surveys,

561 recommended to survey bats (Loeb et al. 2015). Stationary surveys are further separated into

562 survey methods in which a single detector is strategically located ('single strategic') and multiple

563 detectors are spatially replicated across the landscape ('spatially replicated'). The effectiveness

564 of these survey methods at detecting species richness and rare species were tested in Everglades

565 National Park, Florida.

\begin{tabular}{|c|c|c|}
\hline $\begin{array}{l}\text { SURVEY } \\
\text { METHOD }\end{array}$ & ADVANTAGES & DISADVANTAGES \\
\hline $\begin{array}{l}\text { Mobile Driving } \\
\text { Transect Surveys }\end{array}$ & $\begin{array}{l}\text { - Allows estimates of bat abundance } \\
\text { - Enables sampling of a large spatial } \\
\text { area in one night } \\
\text { - Allows sampling of areas that may be } \\
\text { inaccessible for other survey } \\
\text { techniques (e.g., private lands) } \\
\text { - Low cost (e.g., requires only one } \\
\text { detector) }\end{array}$ & $\begin{array}{l}\text { - Introduces spatial sampling biases (e.g., some } \\
\text { bat species may avoid or be attracted to roads) } \\
\text { - Provides limited spatial sampling (sampling is } \\
\text { restricted to locations \& habitats where roads } \\
\text { are constructed) } \\
\text { - Provides limited temporal sampling (e.g., } \\
\text { transects are typically surveyed only a few } \\
\text { hours per night) } \\
\text { - Introduces temporal sampling biases (areas } \\
\text { along the transect are sampled only briefly) } \\
\text { - Labor intensive (e.g., requires an individual to } \\
\text { drive throughout the duration of the survey) }\end{array}$ \\
\hline $\begin{array}{l}\text { Stationary Point } \\
\text { Surveys }\end{array}$ & $\begin{array}{l}\text { - Low investment of labor (equipment is } \\
\text { left to sample many hours after } \\
\text { deployment) } \\
\text { - High temporal sampling replication } \\
\text { (equipment can record all night for } \\
\text { multiple nights) }\end{array}$ & $\begin{array}{l}\text { - Does not allow estimates of bat abundance } \\
\text { - Provides limited spatial sampling (only one } \\
\text { location is sampled per detector) }\end{array}$ \\
\hline Single strategic & $\begin{array}{l}\text { - Enables purposeful maximization of } \\
\text { bat detections (e.g., if detectors are } \\
\text { placed near water or other areas } \\
\text { expected to have high bat activity } \\
\text { levels) } \\
\text { - Low investment of labor (equipment is } \\
\text { left in one place permanently) }\end{array}$ & $\begin{array}{l}\text { - Provides limited spatial sampling (does not } \\
\text { capture landscape heterogeneity) }\end{array}$ \\
\hline $\begin{array}{l}\text { Spatially } \\
\text { replicated }\end{array}$ & $\begin{array}{l}\text { - Provides spatial replication (captures } \\
\text { landscape heterogeneity) }\end{array}$ & $\begin{array}{l}\text { - Labor intensive (requires deployment of } \\
\text { equipment at multiple sites) }\end{array}$ \\
\hline
\end{tabular}


567 Table 2. Bat species suspected to occur in Everglades National Park, FL that were detected (1) or

568 not detected ( 0 ) by each survey method, vegetation community and season. Abbreviations: SS =

569 Single Strategic, $\mathrm{SR}=$ Spatially Replicated, MT = Mobile Transect.

\begin{tabular}{|c|c|c|c|c|c|c|c|c|c|c|c|c|c|}
\hline \multirow[b]{3}{*}{ BAT SPECIES } & \multirow{2}{*}{\multicolumn{3}{|c|}{$\begin{array}{c}\text { SURVEY } \\
\text { METHOD } \\
\text { Overall }\end{array}$}} & \multicolumn{6}{|c|}{ VEGETATION } & \multicolumn{4}{|c|}{ SEASON } \\
\hline & & & & \multicolumn{2}{|c|}{ Mangrove } & \multicolumn{2}{|c|}{ Pineland } & \multicolumn{2}{|c|}{ Prairie } & \multicolumn{2}{|c|}{ Dry } & \multicolumn{2}{|c|}{ Wet } \\
\hline & SS & SR & MT & SS & MT & SS & MT & SS & MT & SS & MT & SS & MT \\
\hline $\begin{array}{l}\text { Corynorhinus } \\
\text { rafinesquii }\end{array}$ & 1 & 1 & 0 & 0 & 0 & 0 & 0 & 1 & 0 & 0 & 0 & 1 & 0 \\
\hline Eumops floridanus & 1 & 1 & 0 & 1 & 0 & 1 & 0 & 1 & 0 & 1 & 0 & 1 & 0 \\
\hline Eptesicus fuscus & 1 & 1 & 1 & 1 & 1 & 1 & 0 & 1 & 1 & 1 & 1 & 1 & 1 \\
\hline $\begin{array}{l}\text { Lasiurus intermedius } \\
\text { L. borealis/L. }\end{array}$ & 1 & 1 & 1 & 1 & 1 & 1 & 1 & 1 & 0 & 1 & 1 & 1 & 1 \\
\hline seminolus & 1 & 1 & 1 & 1 & 1 & 1 & 1 & 1 & 1 & 1 & 1 & 1 & 1 \\
\hline Molossus molossus & 1 & 1 & 0 & 1 & 0 & 1 & 0 & 0 & 0 & 1 & 0 & 1 & 0 \\
\hline Myotis austroriparius & 0 & 0 & 0 & 0 & 0 & 0 & 0 & 0 & 0 & 0 & 0 & 0 & 0 \\
\hline Nycticeius humeralis & 1 & 1 & 1 & 1 & 1 & 1 & 1 & 1 & 1 & 1 & 1 & 1 & 1 \\
\hline Perimyotis subflavus & 1 & 1 & 1 & 1 & 1 & 1 & 1 & 1 & 0 & 0 & 0 & 1 & 1 \\
\hline Tadarida brasiliensis & 1 & 1 & 1 & 1 & 1 & 1 & 1 & 1 & 1 & 1 & 1 & 1 & 1 \\
\hline Species Richness & 9 & 9 & 6 & 8 & 6 & 8 & 5 & 8 & 4 & 7 & 5 & 9 & 6 \\
\hline
\end{tabular}


572 Table 3. Comparison of estimated effort and costs among three acoustic survey methods used for

573 one season (40-nights) of sampling in Everglades National Park, FL. Effort is reported as an

574 estimated number of person-hours. Labor and analysis costs were derived from these estimates of

575 effort.

\begin{tabular}{|c|c|c|c|c|}
\hline & & \multirow[b]{2}{*}{$\begin{array}{c}\text { MOBILE SURVEYS } \\
\text { MOBILE } \\
\text { TRANSECT } \\
\text { One } 64 \mathrm{~km} \text { transect } \\
\text { driven every } 5 \text { nights; } \\
10 \text { transects total } \\
\end{array}$} & \multicolumn{2}{|c|}{ STATIONARY SURVEYS } \\
\hline & & & $\begin{array}{c}\text { SINGLE } \\
\text { STRATEGIC* } \\
\text { Three sites sampled } \\
\text { for } 40 \text { nights } \\
\text { simultaneously }\end{array}$ & $\begin{array}{c}\text { SPATIALLY } \\
\text { REPLICATED } \\
\text { Twelve sites sampled } \\
\text { for } 20 \text { nights each; } 6 \\
\text { sites at a time }\end{array}$ \\
\hline \multirow[t]{3}{*}{$\begin{array}{l}\text { EFFORT } \\
\text { (HOURS) }\end{array}$} & Field work & $45 \mathrm{~h}$ & $50 \mathrm{~h}$ & $80 \mathrm{~h}$ \\
\hline & Analysis & $15 \mathrm{~h}$ & $30 \mathrm{~h}$ & $60 \mathrm{~h}$ \\
\hline & Total effort & $60 \mathrm{~h}$ & $80 \mathrm{~h}$ & $140 \mathrm{~h}$ \\
\hline \multirow[t]{6}{*}{ COST (USD) } & Equipment $^{1}$ & $\$ 3,100$ & $\$ 8,500$ & $\$ 12,300$ \\
\hline & Vehicle $^{2}$ & $\$ 450$ & $\$ 370$ & $\$ 480$ \\
\hline & Field work ${ }^{3}$ & $\$ 540$ & $\$ 600$ & $\$ 960$ \\
\hline & Analysis $^{3}$ & $\$ 180$ & $\$ 360$ & $\$ 720$ \\
\hline & Total cost & $\$ 4,270$ & $\$ 9,830$ & $\$ 15,460$ \\
\hline & $\begin{array}{r}\text { Cost / Survey } \\
\text { night }^{4}\end{array}$ & $\$ 117$ & $\$ 33$ & $\$ 79$ \\
\hline \multirow[t]{3}{*}{ SUMMARY } & Total effort & LOW & MID & HIGH \\
\hline & Total cost & LOW & MID & HIGH \\
\hline & $\begin{array}{r}\text { Cost / Survey } \\
\text { night }\end{array}$ & HIGH & LOW & MID \\
\hline
\end{tabular}

576 "Estimates are based on all three stationary detector locations (mangroves, prairies, pinelands)

$577 \quad{ }^{1}$ Equipment cost includes detectors, microphones and acoustic analysis software.

$578{ }^{2}$ Vehicle cost was estimated based on rate of $\$ 0.45 /$ mile.

$579{ }^{3}$ Field work and analysis time costs were based on a technician pay rate of $\$ 12.00 /$ hour.

$580{ }^{4}$ Calculation excludes equipment costs, which do not change with number of survey nights 


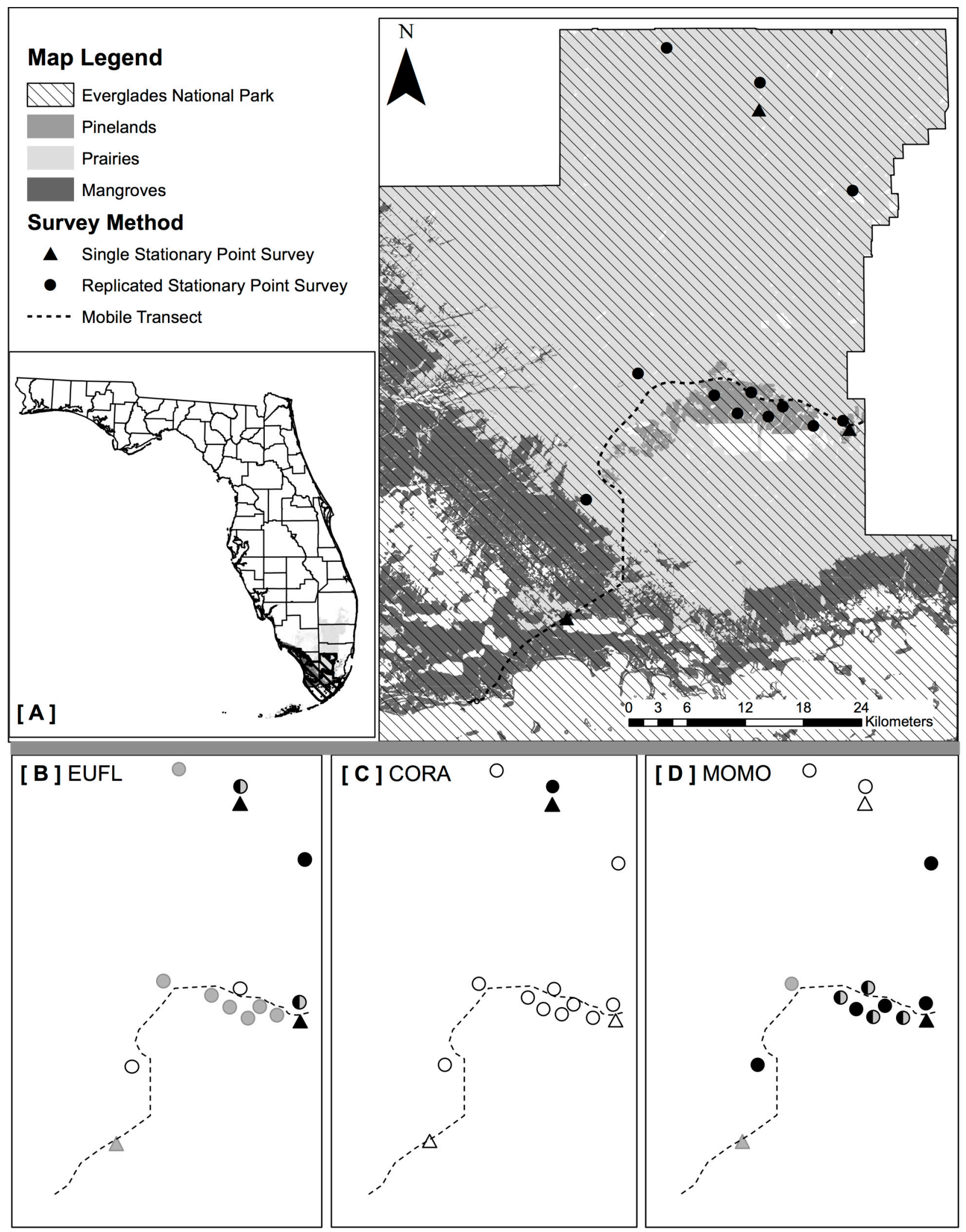


584 Fig. 1. [A] Map of acoustic detector locations for each survey method across Everglades

585 National Park, Florida, U.S.A.; created with GIS data from the Florida Natural Areas Inventory

586 (FNAI 2015; Cooperative Land Cover Map, v3.1). [B - D] show locations of stationary detectors

587 where rare bat species $(\mathrm{EUFL}=$ Eumops floridanus $[\mathrm{B}], \mathrm{CORA}=$ Corynorhinus rafinesquii $[\mathrm{C}]$,

$588 \mathrm{MOMO}=$ Molossus molossus $[\mathrm{D}]$ ) were detected on the same nights and times when mobile

589 transects were conducted (black symbols), detected on the same nights but at different times (e.g.,

590 later in the night) than when mobile transects were conducted (half-black symbols), detected on

591 different nights than when transects were conducted (gray symbols), or not ever detected (open

592 symbols). Mobile transects did not detect these three species during the study. 
Dry Season

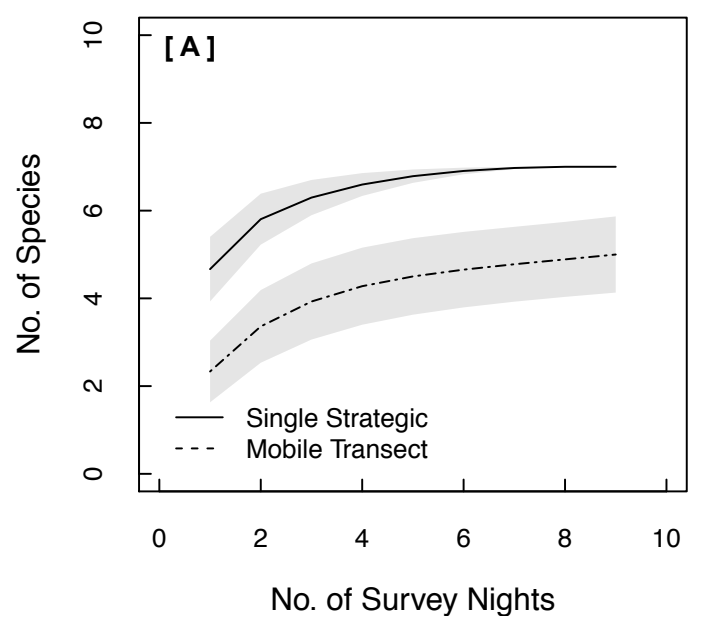

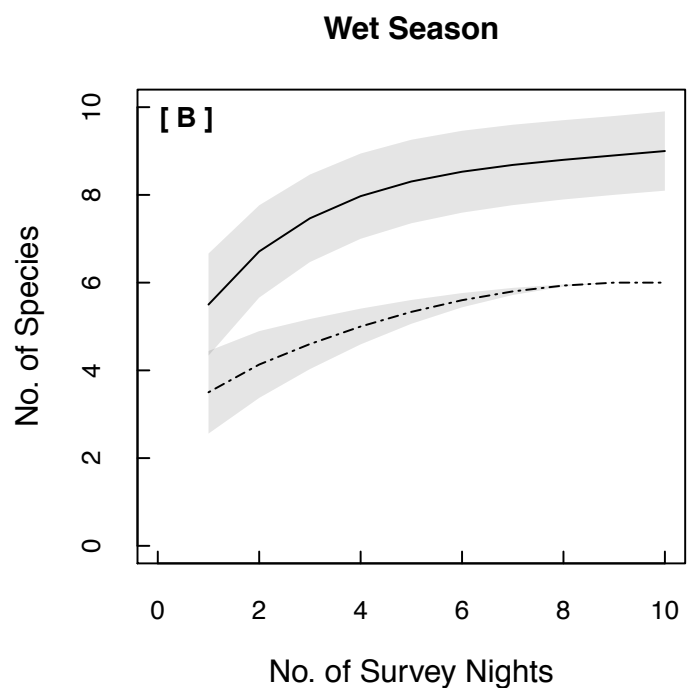

594

595 Fig. 2 Species Accumulation Curves (SACs) across survey nights showing significant

596 differences in expected species richness between single strategic stationary and mobile transect

597 surveys in both [A] the dry season and [B] the wet season. To account for uneven sample effort

598 between methods, this comparison was limited to the same number of survey nights used for

599 mobile transects. Gray shading represents 84\% confidence intervals (Gotelli \& Colwell 2011).

600 

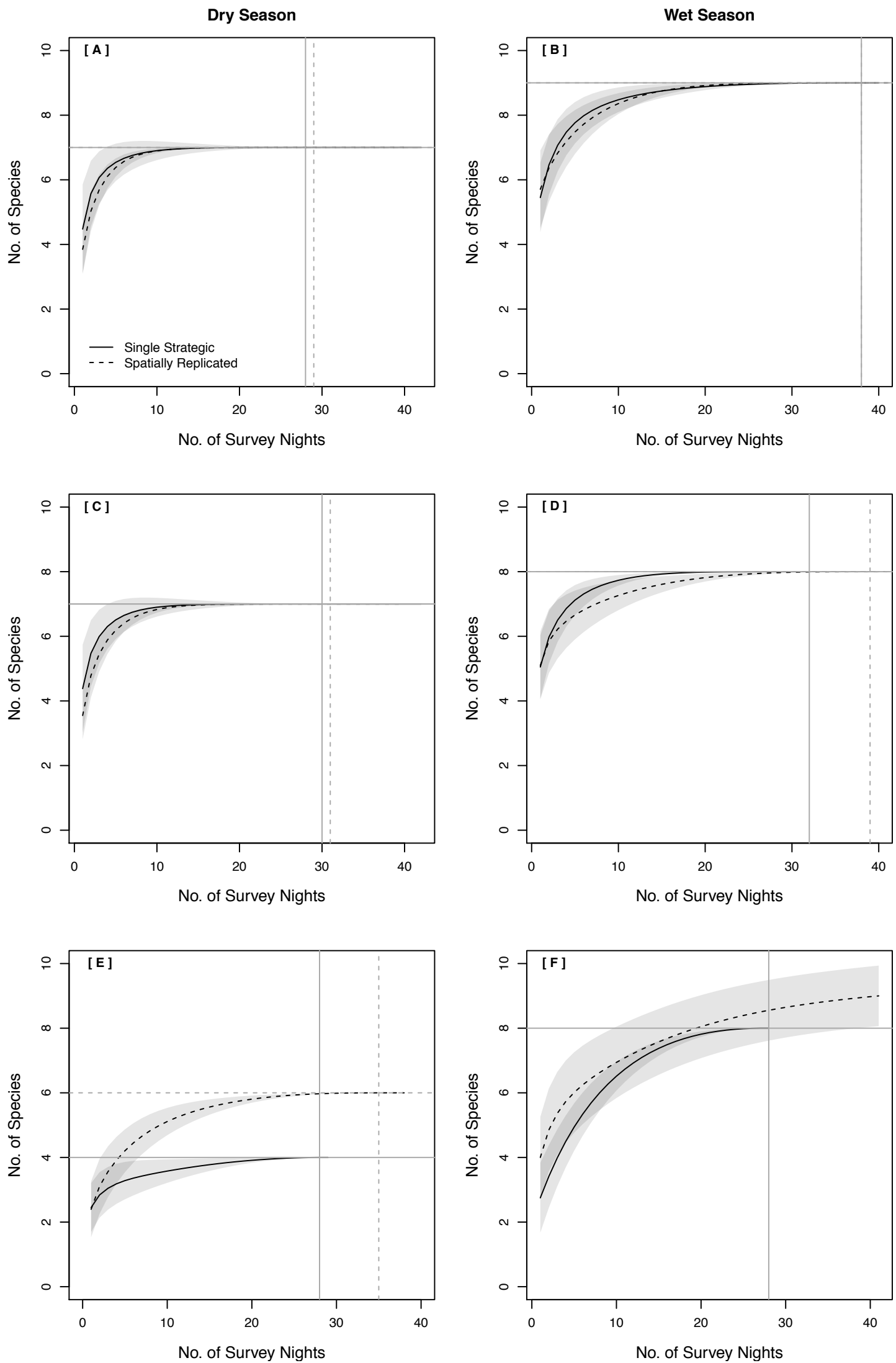
602 Fig. 3 Species Accumulation Curves (SACs) across survey nights showing differences between single 603 strategic and spatially replicated stationary survey methods: [A - B] overall (across both pinelands and 604 prairies), $[\mathrm{C}-\mathrm{D}]$ in pinelands and $[\mathrm{E}-\mathrm{F}]$ in prairies. Gray shading represents $84 \%$ confidence intervals 605 (Gotelli \& Colwell 2011). Gray cross-bars indicate the point at which an asymptote was reached for each 606 SAC, and the corresponding estimated species richness (y-axis) and sample effort (x-axis). 
608
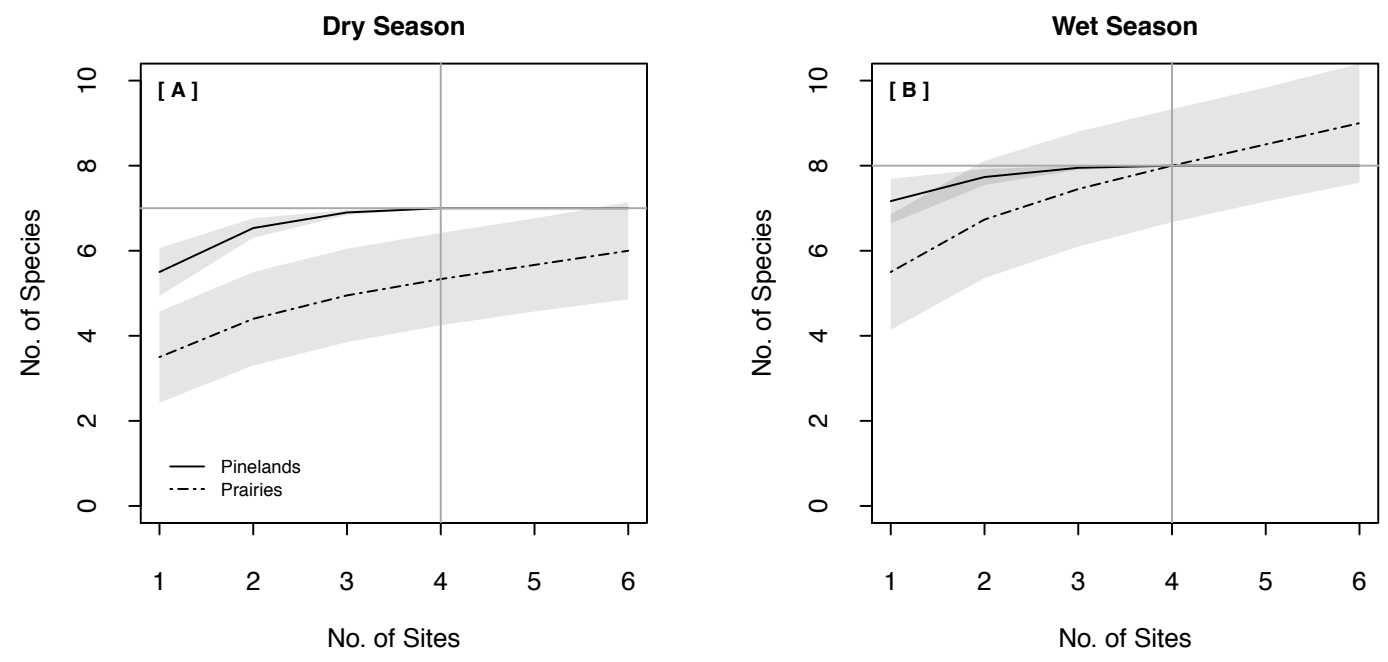

609

610 Fig. 4. Species Accumulation Curves (SACs) for replicated stationary point surveys showing

611 differences in the optimal number of detector sites between pinelands and prairies in [A] the dry

612 season and [B] the wet season. Gray shading represents $84 \%$ confidence intervals. Gray cross-

613 bars indicate the point at which an asymptote was reached for each SAC, and the corresponding

614 estimated species richness (y-axis) and sample effort (x-axis). 


\section{References}

616 Anderson DR. 2001. The need to get the basics right in wildlife field studies. Wildlife Society $617 \quad$ Bulletin 29:1294-1297.

618 Arroyo-Cabrales J, and Álvarez-Castañeda ST. 2008. Corynorhinus rafinesquii. The IUCN Red 619 List of Threatened Species 2008: eT17600A7167222en Downloaded on 20 February 2016.

620 Bates D, Maechler M, and Bolker B. 2012. 1me4: Linear mixed-effects models using S4 classes. 621 R package version 0.999999-0. http://CRAN.R-project.org/package=lme4.

622 Battersby J. 2010. Guidelines for surveillance and monitoring of European bats. EUROBATS

623 Publication Series No. 5., UNEP/EUROBATS Secretariat. Bonn, Germany.

624 Bean MJ, and Rowland MJ. 1997. The evolution of national wildlife law: third edition.

625 Environmental Defense Fund, World Wildlife Fund (US), Greenwood Publishing 626 Group:544.

627 Britzke E. 2003. Use of ultrasonic detectors for acoustic identification and study of bat ecology 628 in the eastern United States. Ph.D. dissertation, Tennessee Technological University, 629 Cookeville, TN.

630 Britzke ER, Gillam EH, and Murray KL. 2013. Current state of understanding of ultrasonic detectors for the study of bat ecology. Acta Theriologica 58:109-117. papers2://publication/doi/10.1007/s13364-013-0131-3

633 Britzke ER, Murray KL, Heywood J, Robbins LW, Kurta A, and Kennedy J. 2002. Acoustic 634 identification. In: Kurta A, and Kennedy J, eds. The Indiana bat: biology and 635 management of an endangered species. Austin, TX: Bat Conservation International, xii + 636253. 
637 Catto C, Russ J, and Langton S. 2003. Development of a car survey monitoring protocol for the 638 Republic of Ireland. Prepared on behalf of the Heritage Council by the Bat Conservation 639 Trust UK, The Heritage Council, Ireland.

640 Chiarucci A, Bacaro G, Rocchini D, and Fattorini L. 2008. Discovering and rediscovering the 641 sample-based rarefaction formula in the ecological literature. Community Ecology 9:121642 123.

643 Ciechanowski M, Zajac T, Bilas A, and Dunajski R. 2007. Spatiotemporal variation in activity of 644 bat species differing in hunting tactics: effects of weather, moonlight, food abundance, 645 and structural clutter. Canadian Journal of Zoology 85:1249-1263.

646 Coleman LS, Ford WM, Dobony CA, and Britzke ER. 2014. Effect of passive acoustic sampling 647 methodology on detecting bats after declines from white nose syndrome. Journal of 648 Ecology and The Natural Environment 6:56-64. 10.5897/JENE2013.0424

649 Colwell R, Mao C, and Chang J. 2004. Interpolating, extrapolating and comparing incidence$650 \quad$ based species accumulation curves. Ecology 85:2717-2727.

651 Colwell RK, Chao A, Gotelli NJ, Lin SY, Mao CX, Chazdon RL, and Longino JT. 2012. Models 652 and estimators linking individual-based and sample-based rarefaction, extrapolation and 653 comparison of assemblages. Journal of Plant Ecology 5:3-21.

654 Conn PB, Moreland EE, Regehr EV, Richmond EL, Cameron MF, and Boveng PL. 2016. Using 655 simulation to evaluate wildlife survey designs: polar bears and seals in the Chukchi Sea. 656 Royal Society Open Science 3:150561.

657 papers2://publication/doi/10.1371/journal.pone.0012114 
658 Duchamp J, Yates M, Muzika R, and Swihart R. 2006. Estimating probabilities of detection for 659 bat echolocation calls: an application of the double-observer method. Wildlife Society $660 \quad$ Bulletin 34:408-412.

661 Duever MJ, Meeder JF, Meeder LC, and McCollom JM. 1994. The climate of south Florida and 662 its role in shaping the Everglades ecosystem. In: Davis SM, and Ogden JC, eds. 663 Everglades: the Ecosystem and Its Restoration. Delray Beach: St. Lucie Press.

664 Ellison AM, Record S, Arguello A, and Gotelli NJ. 2007. Rapid inventory of the ant assemblage 665 in a temperate hardwood forest: Species composition and assessment of sampling 666 methods. Environmental entomology 36:766-775. 10.1603/0046225X(2007)36[766:RIOTAA]2.0.CO;2

668 Fischer J, Stott J, Law B, Adams M, and Forrester R. 2009. Designing effective habitat studies: 669 quantifying multiple sources of variability in bat activity. Acta Chiropterologica 11:127137.

671 Fisher MC, Henk DA, Briggs CJ, Brownstein JS, Madoff LC, McCraw SL, and Gurr. SJ. 2012. 672 Emerging fungal threats to animal, plant and ecosystem health. Nature 484:186-194. 673 Florida Fish and Wildlife Conservation Commission. 2016. Field Guide to Florida Bats. $<$ mmyfwccom/wildlifehabitats/profidles/mammals/land/bats/information/field-guide> $675 \quad$ Downloaded 21 February 2016.

676 Florida Natural Areas Inventory. 2015. Cooperative Land Cover Map, v3.1. September 2015. 677 Froidevaux JSP, Zellweger F, Bollmann K, and Obrist MK. 2014. Optimizing passive acoustic 678 sampling of bats in forests. Ecology and Evolution 4:4690-4700.

679 papers2://publication/doi/10.1002/ece3.1296 
680 Gonzalez FL, Montes AG, Puig E, Johnson S, Mengersen K, and Gaston JK. 2016. Unmanned 681 Aerial Vehicles (UAVs) and artificial intelligence revolutionizing wildlife monitoring $682 \quad$ and conservation. Sensors 16:97. 10.3390/s16010097

683 Gotelli NJ, and Colwell RK. 2001. Quantifying biodiversity: procedures and pitfalls in the 684 measurement and comparison of species richness. Ecology Letters 4:379-391.

685 Gotelli NJ, and Colwell RK. 2011. Estimating species richness. In: Magurran AE, and Mcgill BJ, 686 eds. Biological diversity: frontiers in measurement and assessment. New York: Oxford

688 Hayes J. 1997. Temporal variation in activity of bats and the design of echolocation-monitoring 689 studies. Journal of Mammalogy 78:514-524.

690 Hayes J. 2000. Assumptions and practical considerations in the design and interpretation of 691 echolocation-monitoring studies. Acta Chiropterologica 2:225-236.

692 Hayes JP, Ober HK, and Sherwin RE. 2009. Survey and monitoring of bats. In: Kunz TH, and 693 Parsons S, eds. Ecological and behavioral methods for the study of bats. Baltimore, 694 Maryland, USA: Johns Hopkins University Press, 112-129.

695 Hayes MA. 2013. Bats killed in large numbers at United States wind energy facilities. BioScience 63:975-979.

697 Hayward B, and Davis R. 1964. Flight speeds in western bats. Journal of Mammalogy 45:236698242.

699 Howard PC, Davenport TRB, Kigenyi FW, Viskanic P, Baltzer MC, Dickinson CJ, Lwanga J, 700 Matthews RA, and Mupada E. 2000. Protected area planning in the tropics: Uganda's 701 national system of forest nature reserves. Conservation Biology 14:858-875.

$702 \quad 10.1046 / \mathrm{j} .1523-1739.2000 .99180 . \mathrm{x}$ 
703 IUCN. 2015. The IUCN Red List of Threatened Species. Version 2015-4.

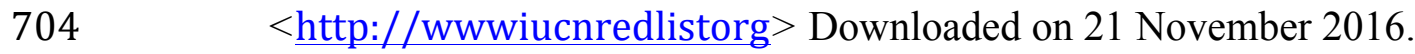

705 Jaberg C, and Guisan A. 2001. Modelling the distribution of bats in relation to landscape

706 structure in a temperate mountain environment. Journal of Applied Ecology 38:1169-

$707 \quad 1181$.

708 Jackrel SL, and Matlack RS. 2010. Influence of surface area, water level and adjacent vegetation 709 on bat use of artificial water sources. The American Midland Naturalist 164:74-79. 10.1674/0003-0031-164.1.74

711 Jones KE, Russ JA, Bashta AT, Bilhari Z, Catto C, Csosz I, Gorbachev A, Gyorfi P, Hughes A,

712 Ivashkiv I, and al. e. 2013. Indicator bats program: a system for the global acoustic

713 monitoring of bats. In: Collen B, Pet-Torelli N, Baillie JEM, and Durant SM, eds.

714 Biodiversity Monitoring and Conservation: bridging the gap between global commitment

715 and local action. Oxford, UK: Wiley-Blackwell, xiv +448.

716 Joppa LN, and Pfaff A. 2009. High and far: Biases in the location of protected areas. Plos One

717 4:e8273. papers2://publication/doi/10.1371/journal.pone.0008273.s002

718 Jung K, Kaiser S, Bohm S, Nieschulze J, and Kalko EKV. 2012. Moving in three dimensions:

719 effects of structural complexity on occurrence and activity of insectivorous bats in

720 managed forest stands. Journal of Applied Ecology 49:523-531.

721 Jung K, Molinari J, and Kalko EKV. 2014. Driving factors for the evolution of species-specific 722 echolocation call design in New World free-tailed Bats (Molossidae). Plos One 9:e85279. 723 10.1371/journal.pone.0085279 
724 Kindt R, Vandamme P, and Simons A. 2006. Patterns of species richness at varying scales in

725 western Kenya: planning for agroecosystems diversification. Biodiversity and

726 Conservation 15:1253-1270.

727 Klinck H, Fregosi S, Matsumoto H, Turpin A, Mellinger DK, Erofeev A, Barth JA, Shearman

728 RK, Jafarmadar K, and Stelzer R. 2016. Mobile autonomous platforms for passive-

729 acoustic monitoring of high-frequency cetaceans. In: Friebe A, and Haug F, eds. Robotic

730 Sailing 2015: Proceedings of the 8th International Robotic Sailing Conference. Cham:

731 Springer International Publishing, 29-37.

732 Korine C, Adams R, Russo D, Fisher-Phelps M, and Jacobs D. 2016. Bats and water:

733 Anthropogenic alterations threaten global bat populations. In: Voigt CC, and Kingston T,

734 eds. Bats in the Anthropocene: Conservation of bats in a changing world. Cham:

735 Springer International Publishing, 215-241.

736 Korner-Nievergelt F, Roth T, Felten S, Guelat J, Almasi B, and Korner-Nievergelt P. 2015.

737 Bayesian data analysis in ecology using linear models with R, BUGS and Stan: Elsevier.

738 Kunz TH. 1982. Ecology of bats. New York, NY: Plenum Press.

739 Kunz TH, Braun de Torrez EC, Bauer DM, Lobova T, and Fleming TH. 2011. Ecosystem

740 services provided by bats. Annals of the New York Academy of Sciences 1223:1-38.

741 Law B, Gonsalves L, Tap P, Penman T, and Chidel M. 2015. Optimizing ultrasonic sampling

742 effort for monitoring forest bats. Austral Ecology 40:886-897.

743 papers2://publication/doi/10.1111/aec.12269

744 Lemen C, Freeman PW, White JA, and Andersen BR. 2015. The problem of low agreement

745 among automated identification programs for acoustical surveys of bats. Western North

746 American Naturalist 75:218-225. 10.3398/064.075.0210 
747 Linchant J, Lisein J, Semeki J, Lejeune P, and Vermeulen C. 2015. Are unmanned aircraft

748 systems (UASs) the future of wildlife monitoring? A review of accomplishments and

749 challenges. Mammal Review 45:239-252. 10.1111/mam.12046

750 Linton DM. 2009. Bat ecology and conservation in lowland farmland. Oxford: University of

$751 \quad$ Oxford.

752 Lodge TE. 2010. The Everglades handbook: understanding the ecosystem. Boca Raton, FL: CRC

753 Press.

754 Loeb SC, T.J. Rodhouse, L.E. Ellison, C.L. Lausen, J.D. Reichard, K.M. Irvine, T.E. Ingersoll,

755 J.T.H. Coleman, W.E. Thogmartin, J.R. Sauer, C.M. Francis, M.L. Bayless, T.R. Stanley,

756 and Johnson DH. 2015. A plan for the North American Bat Monitoring Program (NABat).

757 General Technical Report SRS-208. U.S. Department of Agriculture Forest Service,

$758 \quad$ Southern Research Station. Asheville, NC. p 112.

759 Longino JT, Coddington, J. \& Colwell, R.K. 2002. The ant fauna of a tropical rain forest:

760 estimating species richness three different ways. Ecology 83:689-702.

761 Maltby E, and Dugan PJ. 1994. Wetland ecosystem management, and restoration: An

762 international perspective. In: Davis S, and Ogden J, eds. Everglades: The ecosystem and

763 its restoration. Boca Raton, FL: St. Lucie Press, 860.

764 Marks CS, and Marks GE. 2006. Bats of Florida. Gainesville, FL: University Press of Florida.

765 McCracken GF, Gillam EH, Westbrook JK, Lee Y-F, Jensen ML, and Balsley BB. 2008.

766 Brazilian free-tailed bats (Tadarida brasiliensis: Molossidae, Chiroptera) at high altitude:

767 links to migratory insect populations. Integrative and Comparative Biology 48:107-118.

$768 \quad 10.1093 /$ icb/icn033 
769 Mickleburgh SP, Hutson AM, and Racey PA. 2002. A review of the global conservation status of

$770 \quad$ bats. Oryx 36:18-34. Doi 10.1017/S0030605301000011

771 Milne D, Fisher A, Rainey I, and Pavey C. 2005. Temporal patterns of bats in the top end of the

772 Northern Territory, Australia. Journal of Mammalogy 86:909-920.

773 Moreno CE, and Halffter G. 2000. Assessing the completeness of bat biodiversity inventories

$774 \quad$ using species accumulation curves. Journal of Applied Ecology 37:149-158.

775 O'Shea TJ, Bogan MA, and Ellison LE. 2003. Monitoring trends in bat populations of the United

776 States and territories: problems and prospects. Wildlife Society Bulletin 31:16-29.

777 papers2://publication/uuid/DD202198-BA90-4ACE-8F02-EA09DB79F992

778 Parsons S, and Szewczak JM. 2009. Detecting, recording, and analyzing the vocalizations of bats.

779 In: Kunz TH, and Parsons S, eds. Ecological and behavioral method for the study of bats.

780 2nd ed. Baltimore, Maryland, USA: Johns Hopkins University Press, 91-111.

781 Patterson AP, and Hardin JW. 1969. Flight speeds of five species of vespertilionid bats. Journal $782 \quad$ of Mammalogy 50:152-153.

783 Payton ME, Greenstone MH, and Schenker N. 2003. Overlapping confidence intervals or

784 standard error intervals: what do they mean in terms of statistical significance? Journal of

785 Insect Science 3.1:34. papers2://publication/uuid/4C7973B1-5383-4EBA-BC1E-

$786 \quad$ 61DBAC313733

787 Purvis A, and Hector A. 2000. Getting the measure of biodiversity. Nature 405:212-219.

788 Roche N, Langton S, Aughney T, Russ JM, Marnell F, Lynn D, and Catto C. 2011. A car-based

789 monitoring method reveals new information on bat populations and distributions in

$790 \quad$ Ireland. Animal Conservation 14:642-651. 10.1111/j.1469-1795.2011.00470.x 
791 Rodhouse TJ, Vierling KT, and Irvine KM. 2011. A practical sampling design for acoustic

792 surveys of bats. The Journal of Wildlife Management 75:1094-1102.

793 papers2://publication/doi/10.1002/jwmg.151

794 Skalak SL, Sherwin RE, and Brigham RM. 2012. Sampling period, size and duration influence measures of bat species richness from acoustic surveys. Methods in Ecology and Evolution 3:490-502. 10.1111/j.2041-210X.2011.00177.x

Stahlschmidt P, and Brühl CA. 2012. Bats as bioindicators - the need of a standardized method for acoustic bat activity surveys. Methods in Ecology and Evolution 3:503-508. 10.1111/j.2041-210X.2012.00188.x

800 Stone EL, Jones G, and Harris S. 2009. Street lighting disturbs commuting bats. Current Biology $801 \quad 19: 1123-1127$.

802 Szewczak JM. 2011. Echolocation call characteristics of eastern US bats (accessed 4 March 2016.

803 Taylor DAR, and Tuttle MD. 2007. Water for wildlife: A handbook for ranchers and range 804 managers. Austin, TX: Bat Conservation International. p 20.

805 United States Fish and Wildlife Service. 2012. Mobile bat acoustical survey protocol.

806 Department of the Interior, Washington, D.C., USA.

807 United States Fish and Wildlife Service. 2013. Endangered and threatened wildlife and plants:

808 Endangered species status for the Florida Bonneted Bat. Federal Register 78(191):6100480961043.

810 Whitby MD, Carter TC, Britzke ER, and Bergeson SM. 2014. Evaluation of mobile acoustic 811 techniques for bat population monitoring. Acta Chiropterologica 16:223-230.

$812 \quad 10.3161 / 150811014 X 683417$ 
813 Wickramasinghe LP, Harris S, Jones G, and Vaughan Jennings N. 2003. Bat activity and species

814 richness on organic and conventional farms: impact of agricultural intensification.

$815 \quad$ Journal of Applied Ecology 40:984-993.

816 Williams JA, O'Farrell MJ, and Riddle BR. 2006. Habitat use by bats in a riparian corridor of the 817 Mojave Desert in southern Nevada. Journal of Mammalogy 87:1145-1153.

818 Yoccoz NG, Nichols JD, and Boulinier T. 2001. Monitoring of biological diversity in space and 819 time. Trends in Ecology and Evolution 16:446-453.

820 Zurcher AA, Sparks DW, and Bennett VJ. 2010. Why the bat did not cross the road? Acta

$821 \quad$ Chiropterologica 12:337-340.

822 Zuur AF, Leno EN, Walker NJ, Savaliev AA, and Smith GM. 2009. Mixed effects models and 823 extensions in ecology with $R$. New York: Springer Science+Business Media.

824 